\title{
S. Paradysz
}

\author{
Wroclaw University of Economics
}

\section{Zarządzanie ryzykiem w tworzeniu wartości na przykładzie przedsiębiorstwa z branży organizatorów turystyki.}

JEL Classification: A10

Słowa kluczowe: zarządzanie wartością i ryzykiem przedsiębiorstwa, zabezpieczenie kontraktami terminowymi, ryzyko walutowe, pozycja krótka w kontraktach terminowych.

Streszczenie: Raport przedstawia strategię zabezpieczającą przedsiębiorstwo, działającego w branży organizatorów turystyki przed ryzykiem zmienności kursów walutowych na przychody jednostki. Strategia ta oparta jest na zabezpieczeniu należności poprzez zastosowanie kontraktów terminowych, zajęcia pozycji short hedg. 
WSTĘP:

Ryzyko walutowe, które związane jest z działalnością przedsiębiorstwa, definiuje się jako bieżącą pozycję lub pozycję przyszłych okresów, albo też przewidywany przyszły składnik aktywów bądź pasywów, denominowany w walucie obcej, który musi być przeliczony na inną walutę według kursu, który nie został jeszcze określony ${ }^{1}$. Pomiaru ryzyka dokonuje się na podstawie miar statystycznych, które oceniają zmienność danych początkowych oraz wrażliwość wyników na ich zmiany. Badane przedsiębiorstwo, którego działalność związana jest z organizatorami turystyki narażone jest na szereg czynników, które będą mieć wpływ na sytuację przychodową oraz w zakresie realizowanych w przyszłości marż. Czynniki te to przede wszystkim poziom kursów walutowych, ceny paliwa lotniczego oraz sytuacja społeczno-gospodarcza w Polsce oraz w krajach UE. W niniejszej pracy będę skupiała się ograniczeniu strat związanych ze zmiennym poziomem kursów walutowych, które wpływają na poziom zrealizowanych przychodów przedsiębiorstwa.

\section{OPIS TEORETYCZNY METODY:}

Analiza scenariuszy jest metodą pośrednią uwzględniającą ryzyko, służącą do analizy ryzyka, które związane jest z zarządzaniem finansami przedsiębiorstwa realizowanym w warunkach niepewności. Metoda ta opiera się na tym, iż dla każdej inwestycji sporządza się prognozę kształtowania się czynników wpływających na wartość obecną netto inwestycji lub też na wartość innej metody badania efektywności projektów inwestycyjnych w warunkach różnych przyszłych scenariuszy rozwoju sytuacji. Analiza scenariusza opiera się na minimum trzech zalecanych scenariuszy:

- najbardziej prawdopodobnego (bazowego),

- optymistyczny,

- pesymistyczny.

W miarę potrzeb wynikających z rzeczywistej sytuacji można opracować więcej takich scenariuszy².

W swojej pracy analizę scenariusza będę opierała na zabezpieczeniu należności przed spadkiem kursu walutowego poprzez zastosowanie metody hedgingu, która wykorzystuje kontrakty terminowe do zabezpieczenia ryzyka. Analiza

\footnotetext{
${ }^{1}$ D. Meniów, Instrumenty zabezpieczające w transakcjach walutowych, AJG, Bydgoszcz 2003, s.102.

${ }^{2}$ G. Michalski, K. Prędkiewicz, Tajniki finansowego sukcesu dla mikrofirm od uruchomienia do stabilnego wzrostu, wydawnictwo C.H. Beck Sp. z o.o., Warszawa 2007, s.106, 109.
} 
scenariusza oparta na kształtowaniu się kursu walutowego będzie opierała się na trzech scenariuszach: bazowym (zrównoważonym), pesymistycznym-spadek kursu walutowego, optymistyczny-wzrost kursu walutowego. Tym samym mając najbardziej pozytywny, najbardziej negatywny oraz wyśrodkowany wariant przyszłego kursu otrzymujemy pełen zakres sytuacji, która może mieć miejsce w przyszłości, z określoną dozą prawdopodobieństwa ${ }^{3}$.

Kontrakty terminowe powstały głównie $\mathrm{z}$ myślą o ich wykorzystaniu w strategiach zabezpieczających, a ponadto kontrakty na kursy walut mogą być wykorzystane przez przedsiębiorstwa, których należności czy zobowiązania są obarczone ryzykiem walutowym. Sama zasada hedgingu opiera się na kontraktach terminowych, które użyjemy w strategii zabezpieczającej, tak aby wygenerowały zyski wtedy, kiedy na instrumencie bazowym ponosimy straty, czyli zyskami z kontraktów pokrywamy straty na instrumencie bazowym. Aby tego dokonać należy w kontrakcie zająć pozycję przeciwną do posiadanej w instrumencie bazowym, czyli posiadając pozycję długą w instrumencie bazowym, kontrakty sprzedajemy lub gdy posiadamy pozycję krótką w instrumencie bazowym, kontrakty terminowe kupujemy. Na przykład:

- $\quad$ w przypadku, gdy jesteśmy importerem i posiadamy zobowiązania w walucie obcej, oznacza to że posiadamy pozycję krótką (spadek kursu waluty obcej będzie pomniejszał wartość posiadanych zobowiązań w walucie narodowej, natomiast obawiamy się wzrostu kursu waluty obcej),

- w przypadku, gdy jesteśmy eksporterem posiadamy należności w walucie obcej, oznacza to, że posiadamy pozycję długą (wzrost kursu waluty obcej będzie powiększał wartość naszych należności w walucie narodowej, natomiast obawiamy się spadku kursu tej waluty). ${ }^{4}$.

\section{STRATEGIA:}

Hedging z wykorzystaniem kontraktów terminowych na euro w celu zabezpieczenia przed spadkiem walutowych należności przedsiębiorstwa. Firma powinna zająć pozycję krótką (short) w kontraktach terminowych. Założenia strategii zabezpieczającej:

- Przedsiębiorstwo wystawiło fakturę na wartość 3625000 EUR w miesiącu sierpień oraz oczekuje spłaty należności do miesiąca września. Do tego czasu obawia się spadku kursu waluty obcej, co może spowodować spadek należności wyrażonych w walucie krajowej. Przy wykorzystaniu kontraktów terminowych na kurs walutowy PLN/EUR firma chce zabezpieczyć się przed ryzykiem walutowym.

\footnotetext{
${ }^{3}$ D. Meniów, Instrumenty zabezpieczające w transakcjach walutowych, AJG, Bydgoszcz 2003, s.93.

${ }^{4}$ K. Mejszutowicz, Podstawy inwestowania w kontrakty terminowe i opcje, Oficjalne wydawnictwo GPW w Warszawie, Warszawa 2008 , s.43.
} 
- Jeden kontrakt na euro notowany na GPW opiewa na 10000 EUR, czyli liczba kontraktów wynosi 360 sztuk (3 $625000 \mathrm{EUR} / 10$ 000EUR = 363).

- Kurs opłacalności dla eksportera wynosi 4,00 PLN/EUR i po takim kursie są również notowane kontrakty.

- $\quad$ Prowizje, depozyty zabezpieczające zostają pominięte.

- Rozpatrywane są trzy scenariusze: bazowy, przy którym kurs walutowy jest równy 4,00 PLN/EUR (p=60\%), pesymistyczny- kurs walutowy równy 3,90 PLN/EUR (p=25\%) oraz optymistyczny, czyli kurs walutowy 4,20 PLN/EUR $(\mathrm{p}=15 \%)$

- Struktura przychodów ze sprzedaży produktów w latach 2010-2013 (tabela 1.) na podstawie danych ze sprawozdań finansowych dla lat 2010-2011 oraz na podstawie raportu Domu Maklerskiego AmerBrokers S.A dla lat 2012-2013. Prognozowanych dla roku 2013 przychód ze sprzedaży wynosi 43500000 EUR, a więc w miesiącu wynosi 3625000 EUR.

Tabela 1. Struktura przychodów ze sprzedaży z podziałem na PLN i EUR

\begin{tabular}{|c|c|c|c|c|}
\hline STRUKTURA & $2010 \mathrm{r}$. & $2011 \mathrm{r}$. & $2012 \mathrm{P} \mathrm{r.}$ & 2013 P r. \\
\hline $\begin{array}{c}\text { całość } \\
\text { przychodów }\end{array}$ & 309068000 & 408874000 & 520000000 & 580000000 \\
\hline w PLN (70\%) & 216347600 & 286211800 & 364000000 & 406000000 \\
\hline w EUR (30\%) & 23180100 & 30665550 & 39000000 & 43500000 \\
\hline
\end{tabular}

Źródło: obliczenia na podstawie por. W. Pluta, Planowanie finansowe w przedsiębiorstwie, Polskie Wydawnictwo Ekonomiczne, Warszawa 2003 oraz http://papers.ssrn.com/sol3/papers.cfm?abstract_id=2238066

Tabela 2. Wynik strategii zabezpieczającej dla podanych założeń

\begin{tabular}{|c|c|c|c|c|}
\hline Scenariusz & Waluta & Bazowy & Pesymistyczny & Optymistyczny \\
\hline Kurs na rynku & PLN/EUR & 4,00 & 3,90 & 4,20 \\
\hline Kurs opłacalności & PLN/EUR & 4,00 & 4,00 & 4,00 \\
\hline Wartość faktury & EUR & 3625000 & 3625000 & 3625000 \\
\hline Przychód & PLN & 14500000 & 14137500 & 15225000 \\
\hline Przychód z kontraktów & PLN & 0 & 362500 & -725000 \\
\hline Wynik na kontraktach & PLN & 14500000 & 14500000 & 14500000 \\
\hline
\end{tabular}

Źródło: obliczenia na podstawie por. K. Mejszutowicz, Podstawy inwestowania w kontrakty terminowe i opcje, Oficjalne wydawnictwo GPW

w Warszawie, Warszawa 2008

Tabela 3. Przedsiębiorstwo stosuje kontrakty terminowe 


\begin{tabular}{|c|c|c|c|c|}
\hline Scenariusz & waluta & bazowy & pesymistyczny & optymistyczny \\
\hline Kurs na rynku & PLN/EUR & 4,00 & 3,90 & 4,20 \\
\hline Kurs opłacalności & PLN/EUR & 4,00 & 4,00 & 4,00 \\
\hline Wartość faktury & EUR & 3625000 & 3625000 & 3625000 \\
\hline Przychód & PLN & 14400000 & 14137500 & 15225000 \\
\hline $\begin{array}{c}\text { Przychód gwarantujący } \\
\text { opłacalność }\end{array}$ & PLN & 14500000 & 14500000 & 14500000 \\
\hline Przychód z kontraktów & PLN & 0 & 360000 & -725000 \\
\hline Saldo & PLN & 14500000 & 14500000 & 14500000 \\
\hline
\end{tabular}

Źródło: obliczenia na podstawie por. K. Mejszutowicz, Podstawy inwestowania w kontrakty terminowe i opcje, Oficjalne wydawnictwo GPW

w Warszawie, Warszawa 2008 oraz http://papers.ssrn.com/sol3/papers.cfm?abstract_id=2238066

Tabela 4. Przedsiębiorstwo nie stosuje kontraktów terminowych

\begin{tabular}{|c|c|c|c|c|}
\hline Scenariusz & waluta & bazowy & pesymistyczny & optymistyczny \\
\hline Kurs na rynku & PLN/EUR & 4 & 3,9 & 4,2 \\
\hline Kurs opłacalności & PLN/EUR & 4 & 4 & 4 \\
\hline Wartość faktury & EUR & 3625000 & 3625000 & 3625000 \\
\hline Przychód & PLN & 14500000 & 14137500 & 15225000 \\
\hline $\begin{array}{c}\text { Przychód gwarantujący } \\
\text { opłacalność }\end{array}$ & PLN & 14500000 & 14500000 & 14500000 \\
\hline Saldo & PLN & 0 & -362500 & 725000 \\
\hline
\end{tabular}

Źródło: obliczenia na podstawie por. K. Mejszutowicz, Podstawy inwestowania w kontrakty terminowe i opcje, Oficjalne wydawnictwo GPW

w Warszawie, Warszawa 2008 oraz http://papers.ssrn.com/sol3/papers.cfm?abstract_id=2238066

Tabela 2. obrazuje wynik strategii zabezpieczającej przed spadkiem kursu walutowego. Zauważa się, iż dzięki stosowaniu kontraktów terminowych przedsiębiorstwo to nie poniesie straty w przypadku spadku kursu walutowego do poziomu 3,90 PLN/EUR, gdyż możliwą stratę rekompensuje zakupione kontrakty terminowe. Z kolei wzrost kursu walutowego do poziomu 4,20 PLN/EUR spowodował, że dzięki kontraktom nie zarobimy dodatkowych 725000 PLN, ale przedsiębiorstwo osiągnie przychód gwarantujący mu opłacalność. Natomiast tabela 3. i tabela 4. opisują sytuację przedsiębiorstwa, gdy stosuje kontrakty terminowe oraz gdy ich nie stosuje. Przedział zmienności kursów walutowych zawiera się w przedziale 5\%- 2,5\%. Stosowanie kontraktów terminowych ma na celu ograniczenie ryzyka związanego ze znaczą stratą. Przedsiębiorstwo to zabezpieczyło się przed możliwie osiągniętym stratami z tytułu ryzyka walutowego.

Reasumując, prognozowanie kursów jest bardzo ryzykowne i niestety często nie przynosi oczekiwanych rezultatów. Poza tym stworzenie rzetelnego modelu uwzględniającego ogrom czynników mogących mieć wpływ na przyszły kurs 
walutowy wydaje się niemożliwe ${ }^{5}$. Mimo to przedsiębiorstwa powinny korzystać z strategii zabezpieczających, jakie oferuje im Giełda Papierów Wartościowych, by móc uniknąć dużych strat wynikających z ryzyka walutowego.

\footnotetext{
${ }^{5}$ D. Meniów, Instrumenty zabezpieczające w transakcjach walutowych, AJG, Bydgoszcz 2003, s.93.
} 


\section{Bibliografia:}

1. Michalski Grzegorz, Strategie finansowe przedsiębiorstw (Entrepreneurial financial strattegies), oddk, Gdańsk 2009.

2. Michalski Grzegorz, Ocena finansowa kontrahenta na podstawie sprawozdań finansowych (Financial Analysis in the Firm. A Value-Based Liquidity Framework), oddk, Gdańsk 2008.

3. Michalski, Grzegorz Marek, Wprowadzenie do zarządzania finansami przedsiębiorstw, (Introduction to Entrepreneurial Financial Management), Available at SSRN: http://ssrn.com/abstract=1934041 or http://dx.doi.org/10.2139/ssrn.1934041

4. Michalski Grzegorz (2007), Portfolio Management Approach in Trade Credit Decision Making, Romanian Journal of Economic Forecasting, Vol. 3, pp. 42-53, 2007. Available at SSRN: http://ssrn.com/abstract=1081269

5. Michalski Grzegorz (2008), Operational risk in current assets investment decisions: Portfolio management approach in accounts receivable, Agricultural Economics-Zemedelska Ekonomika, 54, 1, 12-19

6. Michalski Grzegorz (2008), Corporate inventory management with value maximization in view, Agricultural Economics-Zemedelska Ekonomika, 54, 5, 187-192.

7. Michalski Grzegorz (2009), Inventory management optimization as part of operational risk management, Economic Computation and Economic Cybernetics Studies and Research, 43, 4, 213-222.

8. Michalski Grzegorz (2011), Financial Analysis in the Enterprise: A Value-Based Liquidity Frame-work. Available at SSRN: http://ssrn.com/abstract=1839367, 177-262.

9. Michalski Grzegorz (2007), Portfolio management approach in trade credit decision making, Romanian Journal of Economic Forecasting, 8, 3, 42-53.

10. Michalski Grzegorz (2008), Value-based inventory management, Romanian Journal of Economic Forecasting, 9, 1, 82-90.

11. Michalski Grzegorz (2012), Financial liquidity management in relation to risk sensitivity: Polish enterprises case, Quantitative Methods in Economics, Vydavatelstvo EKONOM, Bratislava, 141-160.

12. Michalski Grzegorz (2008), Decreasing operating risk in accounts receivable mangement: influence of the factoring on the Enterprise value, [in] Culik, M., Managing and Modelling of Financial Risk, 130-137.

13. Dudycz Tadeusz, Zarządzanie wartością przedsiębiorstwa, Polskie Wydawnictwo Ekonomiczne

14. Michalski Grzegorz (2010) Planning optimal from the Enterprise value creation perspective. Levels of operating cash investment. Romanian Journal of Economic Forecasting vol. 13 iss 1 pp 198-214 
15. Polak Petr, Robertson, D. C. and Lind, M. (2011), The New Role of the Corporate Treasurer: Emerging Trends in Response to the Financial Crisis (December 12, 2011). International Research Journal of Finance and Economics, No. 78, Available at SSRN: http://ssrn.com/abstract=1971158

16. Soltes Vincent (2012), Paradigms of Changes in the 21th Century - Quest for Configurations in Mosaic, Ekonomicky Casopis, v.60 is.4 pp. 428-429.

17. Soltes Vincent (2011), The Application of the Long and Short Combo Option Strategies in the Building of Structured Products, 10th International Conference of Liberec Economic Forum, Liberec.

18. Zmeskal Zdenek, Dluhosova Dana (2009), Company Financial Performance Prediction on Economic Value Added Measure by Simulation Methodology, 27th International Conference on Mathematical Methods in Economics, Mathematical Methods in Economics, 352-358.

19. Polak Petr, Sirpal R., Hamdan M. (2012), Post-Crisis Emerging Role of the Treasurer, European Journal of Scientific Research, 86, 3, 319-339

20. Kresta A.; Tichy Tomas (2012), International Equity Portfolio Risk Modeling: The Case of the NIG Model and Ordinary Copula Functions, FINANCE A UVER-CZECH JOURNAL OF ECONOMICS AND FINANCE 62, 2, 141161.

21. Kopa Milos, D'Ecclesia RL, Tichy Tomas (2012), Financial Modeling, FINANCE A UVER-CZECH JOURNAL OF ECONOMICS AND FINANCE, 62, 2, 104-105.

22. Michalski, Grzegorz Marek, Value-Based Inventory Management, Value-Based Inventory Management, Journal of Economic Forecasting, 9/1, 82-90, 2008. Available at SSRN: http://ssrn.com/abstract=1081276 or http://dx.doi.org/10.2139/ssrn.1081276

23. Dluhosova Dana, et. al., 2006, Finanční řízení a rozhodování podniku: analýza, investování, oceňování, riziko, flexibilita, Ekopress, Prague.

24. Soltes Vincent, 2004, Duration of coupon bonds as a criterion of the price sensibility of bonds with regards to the change of interest rates (Durácia kupónovej obligácie ako kritérium cenovej citlivosti obligácie vzhl'adom na zmenu úrokových sadzieb in Slovak), EKONOMICKY CASOPIS, 52/2004(1), pp. 108-114.

25. Michalski, Grzegorz Marek, Factoring and the Firm Value (May 17, 2008). FACTA UNIVERSITATIS Series: Economics and Organization, Vol. 5, No. 1, pp. 31-38, 2008. Available at SSRN: http://ssrn.com/abstract=1844306

26. Michalski, Grzegorz Marek, Crisis Caused Changes in Intrinsic Liquidity Value in Non-Profit Institutions (December 14, 2012). Equilibrium. Quarterly Journal of Economics and Economic Policy, 2012, Volume 7, Issue Available at SSRN: http://ssrn.com/abstract=2189488 or http://dx.doi.org/10.2139/ssrn.2189488 
27. Michalski, Grzegorz Marek, Płynność finansowa w małych i średnich przedsiębiorstwach (Financial Liquidity Management in Small and Medium Enterprises) (2013). Płynność Finansowa w Małych i Średnich Przedsiębiorstwach, PWN, 2013. Available at SSRN: $\underline{\text { http://ssrn.com/abstract=2214715 }}$

28. ${ }^{1}$ D. Meniów, Instrumenty zabezpieczające w transakcjach walutowych, AJG, Bydgoszcz 2003.

29. K. Mejszutowicz, Podstawy inwestowania w kontrakty terminowe i opcje, Oficjalne wydawnictwo GPW w Warszawie, Warszawa 2008.

30. http://papers.ssrn.com/sol3/papers.cfm?abstract_id=2238066

31. W. Pluta, Planowanie finansowe w przedsiębiorstwie, Polskie Wydawnictwo Ekonomiczne, Warszawa 2003.

32. G. Michalski, K. Prędkiewicz, Tajniki finansowego sukcesu dla mikrofirm od uruchomienia do stabilnego wzrostu, wydawnictwo C.H. Beck Sp. z o.o., Warszawa 2007.

33. K. Jajuga, Zarządzanie ryzykiem, PWN, Warszawa 2009. 